\title{
TINJAUAN PEMANFAATAN SLUDGE CAKE PABRIK PULP KRAFT SEBAGAI ENERGI ALTERNATIF MELALUI PROSES GASIFIKASI
}

\author{
Syamsudin \\ Balai Besar Pulp dan Kertas \\ Jl. Raya Dayeuhkolot 132, Bandung \\ syamsudin@kemenperin.go.id
}

Diterima : 9 Februari 2015, Revisi akhir : 27 April 2015, Disetujui terbit : 8 Mei 2015

\section{A REVIEW OF UTILIZATION OF SLUDGE CAKE FROM THE KRAFT PULP MILL AS ALTERNATIVE ENERGY THROUGH GASIFICATION PROCESS}

\begin{abstract}
Kraft pulp mills generate large amounts of sludge cake with typical calorific value of $24 \mathrm{MJ} / \mathrm{kg}$ (dry and ash-free basis). Sludge cake could be utilized as an alternative energy through gasification to produce medium gaseous fuel. Sludge cake has a high moisture content and low dewaterability, probably due to biomass from the microbial growth in the wastewater treatment by activated sludge. These problems could be overcome by the addition of filtration aid utilizing biomass waste from pulp mill and dewatering processes by TAMD method. Drying was continued by utilizing hot flue gas from the boiler or lime kiln. Steam gasification of sludge cake by allothermal model could produce a gaseous fuel with a calorific value of $11 \mathrm{MJ} / \mathrm{Nm}^{3}$. Allothermal gasification model of two reactors was able for handling sludge cake with a moisture content of $<55 \%$, but produce gas with a high tar content. Gasification or combustion of sludge cake on this model should be performed at temperatures $>1200^{\circ} \mathrm{C}$ to prevent slagging and fouling problem. In contrast, allothermal gasification model of three reactors could produce gas with a low tar content. Heat of gasification reaction might be supplied from the combustion of volatile gas. Pyrolysis could be performed at temperatures $<500^{\circ} \mathrm{C}$ to permit adequate heat supply for gasification and high char yield. Substitution of natural gas with producer gas need to pay attention to the redesign of the combustion process associated with the lower heat of combustion.
\end{abstract}

Keywords: sludge cake, dewatering, gasification, steam, $\mathrm{CO}_{2}$, medium gaseous fuel

\section{ABSTRAK}

Pabrik pulp kraft menghasilkan sludge cake dalam jumlah besar dengan nilai kalor tipikal 20 $\mathrm{MJ} / \mathrm{kg}$ (dasar kering dan bebas abu). Sludge cake dapat dimanfaatkan sebagai energi alternatif melalui gasifikasi untuk menghasilkan bahan bakar gas medium. Sludge cake memiliki kadar air tinggi dan dewaterability rendah, disebabkan adanya biomassa hasil pertumbuhan mikroba pengolahan air limbah secara lumpur aktif. Kendala ini diatasi dengan penambahan media bantu filtrasi memanfaatkan limbah biomassa pabrik pulp dan proses dewatering dengan metode TAMD. Pengeringan dilanjutkan dengan memanfaatkan gas panas dari boiler atau lime kiln. Proses gasifikasi-kukus allothermal terhadap sludge cake dapat menghasilkan gas bakar dengan nilai kalor $11 \mathrm{MJ} / \mathrm{Nm}^{3}$. Gasifikasi allothermal model dua reaktor mampu menangani sludge cake dengan kadar air $<55 \%$, namun menghasilkan gas dengan kadar tar yang tinggi. Gasifikasi atau pembakaran sludge cake pada model ini sebaiknya dilakukan pada suhu di bawah $1200^{\circ} \mathrm{C}$ untuk menghindari terjadinya slagging dan fouling. Sebaliknya, gasifikasi allothermal model tiga reaktor dapat menghasilkan gas dengan kadar tar rendah. Panas reaksi gasifikasi mungkin dapat dipenuhi dari pembakaran gas volatil hasil pirolisis. Pirolisis dapat dilakukan pada suhu $<500^{\circ} \mathrm{C}$ dengan mempertimbangkan kecukupan suplai panas gasifikasi dan yield arang tinggi. Penggantian gas bumi dengan gas produser perlu memperhatikan redesign proses pembakaran terkait dengan panas pembakaran yang lebih rendah.

Kata kunci: sludge cake, dewatering, gasifikasi, kukus, $\mathrm{CO}_{2}$, bahan bakar gas kalor medium 


\section{PENDAHULUAN}

Pabrik pulp kraft merupakan salah satu industri pengkonsumsi energi dalam jumlah besar. Pabrik pulp bleached kraft mengkonsumsi energi panas $10-14 \mathrm{GJ} / \mathrm{ADt}$ (tidak termasuk kukus untuk produksi listrik) dan energi listrik $600-800 \mathrm{kWh} /$ ADt (Ineris, 2010). Konsumsi energi tergantung konfigurasi proses, peralatan proses, dan efisiensi proses. Tantangan pabrik pulp di bidang energi semakin meningkat dengan semakin terbatasnya cadangan dan kenaikan harga bahan bakar fosil, kebijakan energi, peraturan lingkungan yang lebih ketat, dan daya saing global. Kebutuhan untuk beralih dari bahan bakar fosil telah membuka peluang baru untuk penggunaan produk dari sumber energi terbarukan seperti biomassa. Beberapa usaha konservasi dan diversifikasi energi telah dilakukan, antara lain dengan memanfaatkan limbah biomassa yang telah tersedia di dalam pabrik dalam jumlah melimpah. Penggunaan limbah biomassa ini dibatasi oleh tingkat produksi dan metode pengolahannya di dalam pabrik. Meskipun demikian, pabrik pulp memiliki potensial energi yang besar karena memproses bahan lignoselulosa sebagai bahan baku produksi dalam jumlah besar. Beberapa limbah biomassa yang dihasilkan dari pabrik pulp dalam jumlah besar antara lain lindi hitam, kulit dan serbuk kayu dan sludge cake dari instalasi pengolah air limbah (IPAL) (Gavrilescu, 2008). Selain itu, terdapat juga limbah mata kayu (knot), undersize chip dan pulp reject dari proses screening. Ketersediaan limbah biomassa ini memberi peluang bagi pabrik pulp untuk dapat memenuhi sendiri kebutuhan energi dengan integrasi teknologi konversi energi dari berbagai limbah biomassa di dalam prosesnya.

Pabrik pulp kraft memenuhi sebagian besar kebutuhan energi dengan membakar lindi hitam pekat di recovery boiler dan kulit kayu dan sisasisa kayu lainnya di power boiler. Terpentin, tall oil, gas tak terkondensasi dan minyak pirolisis telah dimanfaatkan sebagai bahan bakar lime kiln menggantikan gas bumi dan bahan bakar minyak di pabrik pulp modern. Salah satu sumber energi alternatif baru dan terbarukan potensial yang belum banyak termanfaatkan adalah sludge cake hasil pengolahan air limbah. Fraksi organik dalam sludge cake bersifat renewable dan dianggap tidak berkontribusi terhadap emisi $\mathrm{CO}_{2}\left(\mathrm{CO}_{2}\right.$ neutral).
Pemanfaatan sludge cake sebagai bahan bakar alternatif dapat mengatasi masalah penanganan sludge cake sekaligus mendapatkan sumber energi dari biomassa yang tidak berkontribusi terhadap gas rumah kaca (GRK). Keuntungan utama yang diperoleh dari pemanfaatan sludge cake sebagai bahan bakar, yaitu volume limbah dan luas lahan untuk landfill berkurang karena limbah tersisa sebagai abu, mengurangi biaya transportasi limbah, mereduksi cemaran bau dan air di lokasi penimbunan dan menghasilkan energi (Setiadji, 2002).

Tulisan ini adalah tinjauan untuk membahas potensi sludge cake pabrik pulp kraft sebagai bahan bakar gasifikasi, metode pengeringan yang cocok untuk menangani sludge cake dengan sifat dewaterability rendah, proses pirolisis dan gasifikasi sludge cake yang dapat menghasilkan bahan bakar gas kalor medium, serta aplikasi gasifikasi sludge cake di pabrik pulp kraft.

\section{SLUDGE CAKE PABRIK PULP KRAFT SEBAGAI BAHAN BAKAR}

Pabrik pulp kraft merupakan penghasil sludge cake dalam jumlah besar dari unit IPAL. Ketersediaan sludge cake dari pabrik pulp kraft umumnya mencapai $58 \mathrm{~kg}$ per ton pulp (Scott dkk., 1995). Penanganan dan pengelolaan limbah sludge cake pada umumnya diawali dengan pemekatan secara gravitasi, kemudian didewatering menggunakan alat belt press hingga kadar padatan maksimal $30 \%$ berat atau alat ulir tekan (screw press) hingga kadar padatan maksimal 60\%. Limbah sludge cake umumnya dikelola dengan cara ditimbun di area lokasi pabrik atau di luar pabrik yang memerlukan lahan cukup luas dan memerlukan pengaturan khusus untuk mencegah terjadinya pencemaran (Setiadji, 2002). Penanganan sludge cake membutuhkan biaya besar dan menjadi isu lingkungan yang sensitif. Permasalahan ini menjadi semakin serius dengan bertambahnya jumlah sludge cake melalui peningkatan kapasitas produksi pulp dan semakin ketatnya peraturan lingkungan yang ditetapkan pemerintah. Tantangan yang dihadapi adalah mencari solusi inovatif dan murah untuk menangani sludge cake menjadi bahan bakar dengan memperhatikan isu lingkungan.

Pemanfaatan sludge cake sebagai bahan bakar didasarkan atas potensi yang dimiliki, yaitu mempunyai kadar organik total dan nilai kalor yang cukup tinggi. Sludge cake pabrik pulp pada 
umumnya mengandung zat organik (60 - 80\%) dengan nilai kalor $10-15 \mathrm{MJ} / \mathrm{kg}$ dan kadar abu $22-40 \%$ (Setiadji, 2002). Tipikal kandungan organik sludge cake tersusun dari total selulosa $49,16 \%$, hemiselulosa $6,15 \%$ dan lignin $14,15 \%$ (Syamsudin, 2014). Analisis proksimat, ultimat, lowerheating value (LHV), dankomposisi organik sampel sludge cake dari pabrik pulp proses kraft dibandingkan dengan biomassa lain dan batubara ditampilkan pada Tabel 1. Zat organik dalam sludge cake berasal dari sisa-sisa serat halus yang tidak dapat diambil lagi sebagai bahan baku pulp dan sel-sel mikroba dari pengolahan lumpur aktif. Sludge cake memiliki ukuran partikel kecil sehingga mudah untuk dicampur dengan bahan aditif lain untuk meningkatkan karakteristiknya sebagai bahan bakar dan sifatnya yang hampir homogen selama produksi pulp menggunakan bahan baku yang sama. Pemanfataan sludge cake sebagai bahan bakar semakin prospektif dengan adanya kecenderungan beralihnya pengolahan air limbah pabrik pulp dari pengolahan fisika-kimia menjadi pengolahan biologi saja. Sludge biologi umumnya memiliki nilai kalor lebih tinggi dibandingkan sludge fisika-kimia (dasar kering) karena memiliki kandungan organik lebih tinggi dan kadar abu lebih rendah, meskipun terkendala sifat dewaterability rendah.

Tabel 1. Sifat-Sifat Sludge Cake Pabrik Pulp dan Biomassa Lain

\begin{tabular}{|c|c|c|c|c|c|c|}
\hline No. & Parameter & Sludge Cake $e^{1)}$ & Pulp Reject $t^{3)}$ & Batubara $^{1)}$ & Sekam Padi) & Cangkang Sawit ${ }^{2)}$ \\
\hline \multirow[t]{4}{*}{1.} & \multicolumn{6}{|c|}{ Analisis Proksimat (Dasar Kering): } \\
\hline & a. $\mathrm{Abu}$ & $27,60 \%$ & $5,98 \%$ & $2,77 \%$ & $23,02 \%$ & $1,86 \%$ \\
\hline & b. Zat Terbang & $61,00 \%$ & $75,25 \%$ & $48,80 \%$ & $61,54 \%$ & $76,59 \%$ \\
\hline & c. Karbon Tetap & $11,40 \%$ & $18,77 \%$ & $48,44 \%$ & $15,44 \%$ & $21,55 \%$ \\
\hline \multirow[t]{6}{*}{2.} & \multicolumn{6}{|c|}{ Analisis Ultimat (Dasar Kering): } \\
\hline & a. Karbon & $34,54 \%$ & $43,53 \%$ & $70,64 \%$ & $38,63 \%$ & $55,33 \%$ \\
\hline & b. Hidrogen & $4,29 \%$ & $6,02 \%$ & $4,45 \%$ & $5,34 \%$ & $5,40 \%$ \\
\hline & c. Nitrogen & $1,18 \%$ & $0,39 \%$ & $0,94 \%$ & $0,46 \%$ & $0,34 \%$ \\
\hline & d. Total Sulfur & $0,36 \%$ & $0,56 \%$ & $0,00 \%$ & $0,08 \%$ & $0,07 \%$ \\
\hline & e. Oksigen & $32,03 \%$ & $43,52 \%$ & $21,21 \%$ & $32,47 \%$ & $37,00 \%$ \\
\hline 3. & $\begin{array}{l}\text { LHV, MJ.kg-1 } \\
\text { (Dasar Kering) }\end{array}$ & 13,25 & 16,95 & 24,91 & 15,98 & 20,95 \\
\hline
\end{tabular}

4. Komposisi Abu:
a. $\mathrm{SiO}_{2}$
$58,1 \%$
b. $\mathrm{Fe}_{2} \mathrm{O}_{3}$
$5,55 \%$
c. $\mathrm{Al}_{2} \mathrm{O}_{3}$
$21,9 \%$
d. $\mathrm{Na}_{2} \mathrm{O}$
$1,11 \%$
$0,14 \%$
e. $\mathrm{K}_{2} \mathrm{O}$
$0,78 \%$
$0,17 \%$
f. $\mathrm{CaO}$
$5,43 \%$
$15,78 \%$
g. $\mathrm{MgO}$
$1,20 \%$
$1,83 \%$
h. $\mathrm{TiO}_{2}$
$1,07 \%$
i. $\mathrm{P}_{2} \mathrm{O}_{5}$
$1,84 \%$
j. $\mathrm{SO}_{3}$
$1,12 \%$

2) Syamsudin dan Susanto (2012a)

3) Data Primer Hasil Uji Laboratorium 


\section{KARAKTERISTIK SLUDGE CAKE PABRIK PULP KRAFT}

Karakteristik sludge cake yang perlu diperhatikan terkait pemanfaatannya sebagai bahan bakar selain nilai kalor, yaitu kadar air, kadar abu, komposisi dan titik leleh abu, analisis proksimat dan analisis ultimat. Kelemahan terbesar dari pemanfaatan sludge cake sebagai bahan bakar yaitu memiliki kadar air cukup tinggi dan sifat dewaterability rendah karena banyak mengandung sel-sel mikroba lumpur aktif dan kadar abu yang relatif lebih tinggi dibandingkan biomassa lain. Proses pengeringan sludge cake yang efektif, efisien dan murah hingga siap menjadi bahan bakar perlu mendapat perhatian khusus sehingga bisa mendapat energi surplus. Selain itu, konfigurasi reaktor juga perlu diperhatikan untuk bisa menangani bahan bakar dengan kadar air tinggi.

Pengaruh kadar air terhadap nilai kalor sludge cake dapat dilihat pada Gambar 1. Pada kadar air $80 \%$, nilai kalor sludge cake hanya $0,9 \mathrm{MJ} /$ $\mathrm{kg}$ dan pembakarannya akan menghasilkan suhu adiabatik hanya sekitar $250^{\circ} \mathrm{C}$. Suhu rendah ini tidak memungkinkan untuk terjadinya pembakaran berkelanjutan (Syamsudin, 2014). Secara praktek, kriteria untuk pembakaran bahan bakar limbah padat di dalam unggun terfluidakan adalah memiliki suhu pembakaran adiabatik minimum antara $1050-1100^{\circ} \mathrm{C}$ (Louhimo dan Mullen, 1991). Jika suhu adiabatik lebih rendah dari $1050-1100^{\circ} \mathrm{C}$, maka diperlukan bahan bakar tambahan seperti bahan bakar minyak, bahan bakar gas, batubara atau bahan bakar lain dengan nilai kalor lebih tinggi. Sludge cake kemungkinan dapat dijadikan bahan bakar pada kadar air maksimal 50\% karena menghasilkan suhu flame adiabatik sekitar $1100^{\circ} \mathrm{C}$ sehingga memenuhi syarat sebagai bahan bakar reaktor unggun terfluidakan (Syamsudin, 2014).

Komposisi mineral dalam abu mempengaruhi titik leleh abu. Titik leleh abu menentukan kondisi operasi pada pemanfaatan sludge cake. Titik leleh abu diukur dengan memanaskan sampel abu sampai mengalami perubahan bentuk yaitu initial deformation (IT), softening (ST), hemispherical (HT) dan fluid (FT) (Nurhadi, 2010). Pembakaran sludge cake harus memperhatikan kondisi leleh abu karena dapat menyebabkan fouling yang berlebihan pada peralatan penukar panas. Di dalam tungku pembakaran, mineral dalam abu bertransformasi menjadi oksida dan dapat terlepas dalam bentuk leburan atau dalam keadaan plastis. Abu yang terbawa oleh aliran gas hasil pembakaran dapat menyebakan erosi dan korosi pada permukaan logam yang dilalui. Akibatnya akan berpengaruh pada dinding tungku dan permukaan panas lainnya. Akumulasi dari endapan abu pada dinding tungku akan menghambat proses perpindahan panas dan menurunkan efisiensi boiler. Titik leleh abu sludge cake ditampilkan dalam Tabel 2. Berdasarkan survei lapangan di beberapa industri kertas, suhu

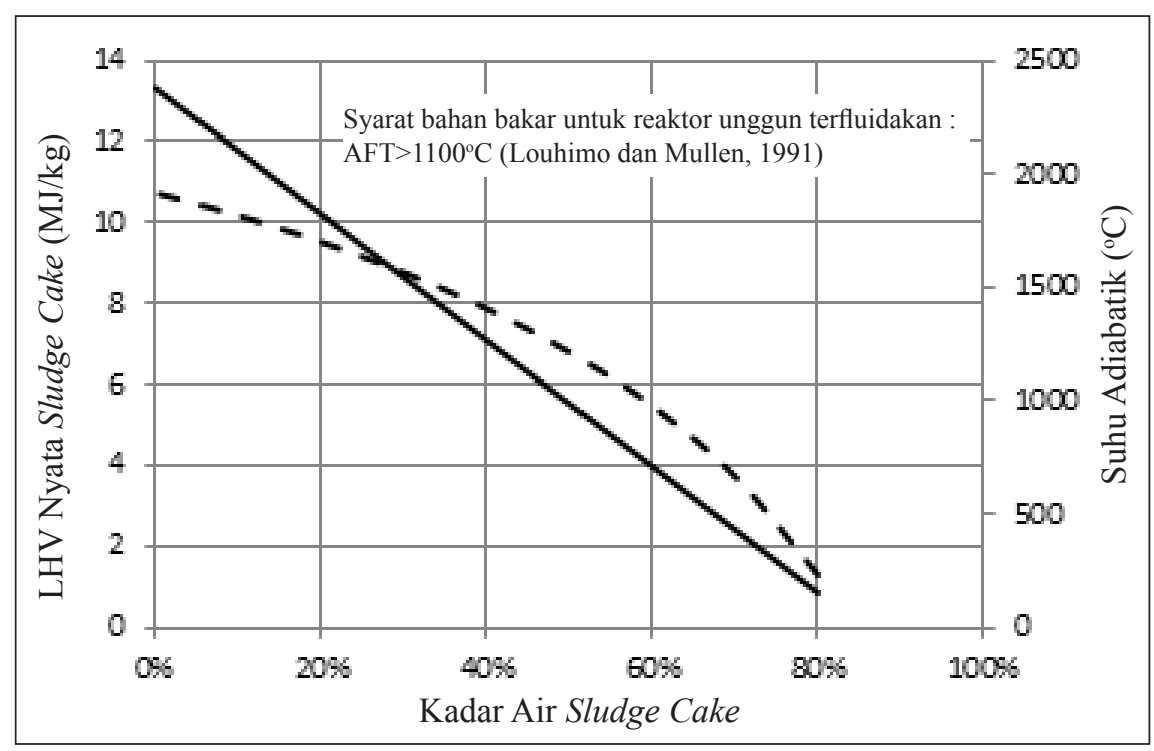

Gambar 1. Pengaruh Kadar Air terhadap Nilai Kalor dan Suhu Pembakaran Sludge Cake

(Syamsudin, 2014) 
Tabel 2. Titik Leleh Abu Sudge Cake

\begin{tabular}{ccccc}
\hline Kondisi & Suhu Deformasi, ${ }^{\circ} \mathrm{C}$ & Suhu Spherikal, ${ }^{\circ} \mathrm{C}$ & Suhu Hemispher, ${ }^{\circ} \mathrm{C}$ & Suhu Alir, ${ }^{\circ} \mathrm{C}$ \\
\hline Reduksi & 1213 & 1233 & 1255 & 1333 \\
Oksidasi & 1265 & 1305 & 1335 & 1415 \\
\hline
\end{tabular}

tungku boiler unggun terfluidakan tersirkulasi (CFB) selama proses pembakaran umumnya sekitar $900^{\circ} \mathrm{C}$ (Setiawan, dkk., 2012). Dilihat dari suhu initial deformation (IT) dan suhu softening (ST) dari sludge cake, maka proses slagging dan fouling tidak terjadi pada pembakaran sludge cake di boiler unggun terfluidakan.

Kandungan zat terbang yang dimiliki sludge cake cukup tinggi dibandingkan kandungan karbon tetap-nya sehingga akan menghasilkan banyak gas volatil pada saat dibakar. Sifat ini memberi keunggulan relatif mudah dinyalakan dan memiliki lidah api yang panjang. Gas volatil yang terbentuk dapat dimanfaatkan untuk bahan bakar gas. Sebaliknya, rendahnya kandungan karbon tetap menyebabkan kemungkinan yield arang hasil pirolisis menjadi rendah jika pirolisis dilakukan pada suhu tinggi. Kondisi ini perlu diperhatikan, terutama jika arang yang diperoleh akan digunakan sebagai bahan bakar. Kandungan oksigen dan nitrogen memberi kontribusi massa, namun tidak memiliki nilai kalor, sehingga menurunkan nilai kalor sludge cake. Tingginya kandungan oksigen dapat menurunkan kebutuhan oksigen dari udara pada proses pembakaran. Kandungan nitrogen yang relatif lebih tinggi dibandingkan biomassa lain menyebabkan potensi emisi $\mathrm{NO}_{\mathrm{x}}$ lebih tinggi pada proses pembakaran. Nitrogen kemungkinan berasal dari biomassa sendiri dan nutrisi yang ditambahkan pada pengolahan biologi di IPAL. Sulfur berkontribusi terhadap nilai kalor sludge cake namun menghasilkan emisi $\mathrm{SO}_{\mathbf{x}}$. Kandungan sulfur kemungkinan berasal dari biomassa itu sendiri dan bahan kimia pemasak yang terbawa dalam sludge cake. Kandungan sulfur yang relatif lebih tinggi dibandingkan biomassa pada umumnya menyebabkan potensi emisi gas $\mathrm{SO}_{\mathrm{x}}$ lebih tinggi pada proses pembakaran. Emisi gas $\mathrm{SO}_{x}$ dapat dicegah antara lain dengan menambahkan batu kapur ke dalam tumpukan material unggun, sedangkan untuk mengontrol emisi gas $\mathrm{NO}_{\mathrm{x}}$ dapat dilakukan antara lain dengan menginjeksikan kukus, ammonia atau urea (Richards, 2000).

\section{PENINGKATAN KUALITAS SLUDGE CAKE SEBAGAI BAHAN BAKAR}

\section{Dewatering dengan Penambahan Media Bantu Filtrasi}

Belt press pada umumnya beroperasi pada tekanan 25 bar. Sludge cake keluaran belt press dengan tekanan ini pada umumnya memiliki kadar air masih di atas 70\%. Kadar air tinggi menurunkan nilai kalor dan berpengaruh menurunkan sifat pembakaran sludge cake. Kadar air dapat diturunkan dengan menambahkan flokulan untuk lebih mengentalkan sludge, namun biaya dewatering menjadi tidak ekonomis. Dewatering dengan pengempaan pada tekanan di atas 400 bar tidak efektif lagi untuk menurunkan kadar air dan hanya menghasilkan kadar air sisa sebesar 53\% (Syamsudin, 2014). Kehadiran air intraseluler dalam sludge biologi menyebabkan proses dewatering mekanik menjadi sulit. Air intraseluler dapat dikeluarkan dengan cara memecah dinding sel melalui perlakuan hidrotermal, kimia, ultrasonik, kimia - panas atau metode freeze-thaw.

Beberapa cara dapat dilakukan untuk meningkatkan sifat dewaterability dari sludge cake, antara lain dengan penambahan media bantu filtrasi. Media bantu filtrasi yang digunakan dapat dibagi menjadi dua kelompok, yaitu kelompok berbasis mineral dan kelompok berbasis karbon. Kelompok berbasis mineral dapat berupa abu terbang, debu kiln semen dan gipsum, sedangkan kelompok berbasis karbon dapat berupa arang, serbuk batubara dan limbah berkarbon seperti serpihan kayu, serbuk gergaji dan sekam padi (Qi, dkk., 2011). Media bantu filtrasi berbasis karbon memiliki kelebihan, yaitu dapat meningkatkan nilai kalor campuran sludge cake. Penambahan serbuk batubara sebagai media bantu filtrasi terbukti dapat memudahkan pengeringan dengan pengempaan dan sekaligus dapat meningkatkan nilai kalor (Qi, dkk., 2011; Syamsudin, 2014). 
Beberapa limbah pabrik pulp yang kemungkinan dapat dimanfaatkan sebagai media bantu filtrasi antara lain abu boiler kayu, kulit kayu, ranting kayu, mata kayu (knot), undersize chip, pulp reject dan limbah dari unit pemulihan kimia seperti lime reject, dreg dan grit. Dari beberapa media bantu filtrasi yang ada, sebaiknya dipilih bahan yang memiliki nilai kalor lebih tinggi dari sludge cake. Lindi hitam dapat ditambahkan untuk meningkatkan nilai kalor sekaligus sebagai bahan perekat. Lindi hitam terbukti efektif meningkatkan nilai kalor dan berfungsi sebagai perekat pada pembuatan biobriket sludge cake industri pulp dan kertas (Syamsudin, dkk., 2007).

\section{Pengeringan Termal Sludge Cake}

Pengurangan kadar air dengan pengeringan termal membutuhkan biaya mahal (Chen dkk., 2006). Kombinasi pengempaan dan pengeringantermal terbukti dapat menghemat energi pengeringan sludge cake (Syamsudin, 2014; Mahmood dkk.,1998; Fernandez dkk., 2005; Mahmoud dkk., 2008). Kombinasi pengempaan 500 bar dilanjutkan dengan pengeringan-termal $110^{\circ} \mathrm{C}$ dapat menghemat energi pengeringan sampai 73\% (Syamsudin, 2014).

Peningkatan dewatering dapat juga dilakukan dengan metode thermal assisted-mechanical dewatering (TAMD), yaitu dengan menambahkan panas secara simultan pada saat proses dewatering. Penambahan panas dimaksudkan untuk memecah dinding sel yang sebelumnya tidak bisa dilakukan dengan dewatering mekanik konvensional. Penggunaan metode TAMD dapat menghemat energi pengeringan mencapai 30\% (Mahmoud dkk., 2011). Metode TAMD dapat diterapkan menggunakan alat ulir tekan berupa ulir tunggal dilengkapi dengan aliran uap di bagian poros dengan tekanan 20 psig (Setiadji, 2002). Lumpur dikeringkan secara bertahap, awalnya secara gravitasi, kemudian ditekan secara bertahap ke arah aksial maupun radial oleh gerakan ulir dan poros yang berbentuk kerucut. Pengeringan dilanjutkan dengan konveyor atau dengan pengering unggun terfluidakan dengan memanfaatkan gas panas proses pembakaran di boiler dengan suhu $180^{\circ} \mathrm{C}$ (Setiadji, 2002) atau gas panas dari lime kiln dengan suhu $200^{\circ} \mathrm{C}$ (setelah melewati electrostatic precipitator). Keistimewaan pengering unggun terfluidakan adalah kemampuannya untuk mendistribusikan gas pengering dengan kecepatan seragam secara merata pada material uggun. Alat pengering ini dapat diandalkan dan mempunyai pengendalian pengeringan yang baik terhadap kondisi pengeringan dan laju pengeringan yang tinggi. Sludge cake kering yang dihasilkan berupa partikel yang ringan dan relatif liat atau tidak mudah hancur sehingga secara fisik dapat digunakan sebagai umpan gasifier unggun tetap maupun gasifier unggun terfluidakan.

\section{Pirolisis Sludge Cake}

Pirolisis adalah degradasi termal bahan yang mengandung karbon tanpa kehadiran media pengoksidasi yang dipasok dari luar sistem dengan melepas zat terbang dari bahan tersebut. Pirolisis pada suhu rendah $300-700^{\circ} \mathrm{C}$ dapat ditujukan untuk upgrading kualitas bahan bakar dengan menghilangkan kadar air dan sebagian zat terbang sehingga diperoleh bahan bakar yang memiliki nilai kalor lebih besar; menghasilkan bahan bakar tanpa asap dengan menghilangkan zat terbang dari bahan tersebut; dan desulfurisasi dengan menyingkirkan senyawa sulfur dalam bahan bakar terutama sulfur organik (Nurhadi, 2010).

Pengamatan yang dilakukan oleh Syamsudin (2014) pada pirolisis non-isotermal sludge cake mengindikasikan terjadinya tiga reaksi yang berhubungan dengan komponen di dalam sludge cake, yaitu reaksi dekomposisi hemiselulosa dan komponen ringan lainnya, reaksi dekomposisi selulosa dan sel mikroba, dan reaksi dekomposisi lignin dan zat-zat anorganik. Menurut Yang, dkk. (2007), hemiselulosa terdegradasi oleh panas pada suhu $220-315^{\circ} \mathrm{C}$ dengan dekomposisi tercepat pada suhu sekitar $270^{\circ} \mathrm{C}$, selulosa tergedradasi pada suhu $315-400^{\circ} \mathrm{C}$ dengan dekomposisi tercepat pada suhu sekitar $350^{\circ} \mathrm{C}$, dan lignin lambat terdegradasi dengan rentang suhu $160-900^{\circ} \mathrm{C}$. Pada percobaan pirolisis isotermal sludge cake, massa sisa akhir reaksi dari pirolisis $500^{\circ} \mathrm{C}$ tidak berbeda jauh dengan massa sisa akhir reaksi dari pirolisis $700^{\circ} \mathrm{C}$, menunjukkan bahwa pirolisis telah selesai pada suhu $500^{\circ} \mathrm{C}$ di mana hemiselulosa, selulosa dan lignin telah habis ter-devolatilisasi. Perbedaan signifikan antara massa sisa akhir reaksi dari pirolisis $400^{\circ} \mathrm{C}$ dengan massa sisa akhir reaksi dari pirolisis $500^{\circ} \mathrm{C}$ dan $700^{\circ} \mathrm{C}$ kemungkinan disebabkan perbedaan jumlah lignin yang dapat didegradasi pada masing-masing suhu pirolisis (Syamsudin, 2014). Hasil ini memberi informasi 
bahwa pirolisis sludge cake cukup dilakukan pada suhu $<500^{\circ} \mathrm{C}$ sehingga dapat menghemat pasokan panas yang diperlukan untuk proses pirolisis.

\section{GASIFIKASI ARANG SLUDGE CAKE}

Insinerasi merupakan salah satu teknik mengurangi volume sludge cake sebelum dibuang ke landfill dan dapat menghasilkan energi untuk pemenuhan sebagian kebutuhan pabrik. Biaya mahal, kesulitan operasi dan kontrol polusi yang ketat menjadi kelemahan dari metode insinerasi. Salah satu cara memanfaatkan sludge cake yang belum banyak digali yaitu mengkonversinya menjadi bahan bakar gas melalui proses gasifikasi. Selain mendapat bahan bakar gas yang bersih, gas hasil proses gasifikasi juga dapat diproses lebih lanjut menjadi DME, bahan bakar diesel melalui proses Fischer-Tropsch, dan gas hidrogen. Gasifikasi dipertimbangkan lebih ramah lingkungan karena emisi gas polutan ke atmosfer yang lebih rendah. Teknologi gasifikasi sludge cake merupakan salah satu pemecahan dalam mencari energi baru terbarukan (EBT) di industri pulp dan kertas yang kini dipandang sebagai teknologi baru yang dapat memenuhi keperluan akan pembangkit tenaga listrik yang bersih dan efisien. Teknologi ini sangat mendukung program pemerintah dalam mengembangkan energi terbarukan dan melaksanakan konservasi energi dalam setiap tahap pelaksanaan usaha. Selain mengatasi masalah penanganan sludge cake yang tidak murah, pemanfaatan sludge cake melalui gasifikasi menghasilkan energi alternatif dalam bentuk bahan bakar gas kalor medium. Selain itu, upaya peningkatan efisiensi energi dan teknologi gasifikasi sludge cake menggantikan insinerasi akan berdampak terhadap penurunan emisi gas rumah kaca. Perbandingan antara gasifikasi dan insinerasi ditampilkan dalam Tabel 3.

Gasifikasi sludge cake merupakan proses konversi termokimia sludge cake dengan agen gasifikasi untuk menghasilkan bahan bakar gas yang disebut gas produser atau syngas. Berdasarkan konfigurasi sistem gasifikasi, kondisi operasi, dan media gasifikasi, dapat dihasilkan empat jenis kualitas gas, yaitu gas dengan nilai kalor rendah $\left(3,5-10 \mathrm{MJ} / \mathrm{m}^{3}\right)$, gas dengan nilai kalor medium $\left(10-20 \mathrm{MJ} / \mathrm{m}^{3}\right)$, gas dengan nilai kalor tinggi $\left(20-35 \mathrm{MJ} / \mathrm{m}^{3}\right)$ dan gas bumi sintetis $(\mathrm{SNG})\left(>35 \mathrm{MJ} / \mathrm{m}^{3}\right)$. Agen gasifikasi dapat berupa udara $\left(21 \% \mathrm{~mol} \mathrm{O}_{2}\right.$ dan $\left.79 \% \mathrm{~mol}_{2}\right)$,

Tabel 3. Perbandingan antara Gasifikasi dan Insinerasi (Arena, 2012)

\begin{tabular}{|c|c|c|c|}
\hline No. & Kriteria & Gasifikasi & Insinerasi \\
\hline 1. & Tujuan & $\begin{array}{l}\text { Memaksimalkan konversi bahan } \\
\text { baku menjadi } \mathrm{CO} \text { dan } \mathrm{H}_{2} \text { untuk } \\
\text { menghasilkan bahan bakar gas } \\
\text { bersih dan ramah lingkungan }\end{array}$ & $\begin{array}{l}\text { Memaksimalkan konversi bahan } \\
\text { baku menjadi } \mathrm{CO}_{2} \text { dan } \mathrm{H}_{2} \mathrm{O} \\
\text { dengan menghasilkan panas }\end{array}$ \\
\hline 2. & Tipe proses & $\begin{array}{l}\text { Konversi termal kimia dalam } \\
\text { kondisi reduksi (jumlah oksigen } \\
\text { terkontrol) }\end{array}$ & $\begin{array}{l}\text { Konversi termal kimia dalam } \\
\text { kondisi oksidasi (oksigen } \\
\text { berlebih) }\end{array}$ \\
\hline 3. & $\begin{array}{l}\text { Komposisi gas } \\
\text { produk }\end{array}$ & $\begin{array}{l}\mathrm{H}_{2}, \mathrm{CO}, \mathrm{CH}_{4}, \mathrm{H}_{2} \mathrm{~S}, \mathrm{NH}_{3} \text {, dan } \\
\text { partikulat }\end{array}$ & $\begin{array}{l}\mathrm{CO}_{2}, \mathrm{H}_{2} \mathrm{O}, \mathrm{SO}_{2}, \mathrm{NO}_{x} \text {, dan } \\
\text { partikulat }\end{array}$ \\
\hline 4. & Pembersihan gas & $\begin{array}{l}\text { - Diperoleh syngas yang dapat } \\
\text { digunakan untuk bahan bakar } \\
\text { bersih, sintesis kimia, atau } \\
\text { pembangkit tenaga } \\
\text { - Sulfur terambil sebagai } \\
\text { komponen S atau asam sulfat }\end{array}$ & $\begin{array}{l}\text { - Flue gas mengandung dioksin } \\
\text { dan furan yang harus diolah } \\
\text { dan hasilnya dibuang ke udara } \\
\text { - Sulfur terkonversi menjadi } \\
\mathrm{SO}_{2} \text { yang harus diolah }\end{array}$ \\
\hline 5. & Produk padatan & Arang atau slag & Bottom ash dan fly ash \\
\hline 6. & $\begin{array}{l}\text { Penanganan produk } \\
\text { samping padatan }\end{array}$ & $\begin{array}{l}\text { - Arang sebagai bahan bakar } \\
\text { - Slag merupakan material non- } \\
\text { leachable dan non-hazardous }\end{array}$ & $\begin{array}{l}\text { Bottom ash dan fly ash ditangani } \\
\text { sebagai limbah B3 }\end{array}$ \\
\hline
\end{tabular}


udara diperkaya $\mathrm{O}_{2}, \mathrm{O}_{2}$ murni, kukus, $\mathrm{CO}_{2}$, atau campuran senyawa-senyawa tersebut (Khalil dkk., 2009; Kumar dkk., 2009; Gao dkk., 2008). Produk gasifikasi mengandung terutama gas $\mathrm{H}_{2}$ dan $\mathrm{CO}$, serta gas-gas lain seperti $\mathrm{CH}_{4}, \mathrm{CO}_{2}, \mathrm{H}_{2} \mathrm{O}$, $\mathrm{N}_{2}$, dan beberapa hidrokarbon berat (tar) (Kumar dkk., 2009; Balat dkk., 2009). Gas produser dapat diolah menjadi bahan bakar gas bersih atau syngas untuk produksi bahan kimia (Higman dan van derBurgt, 2003; Arena, 2012).

Pembakaran berlangsung pada suasana oksidasi dengan mengeluarkan emisi gas $\mathrm{CO}_{2}$, $\mathrm{H}_{2} \mathrm{O}, \mathrm{SO}_{x}, \mathrm{NO}_{x}, \mathrm{HCl}$, partikulat dan gas-gas lain. Sedangkan gasifikasi berlangsung pada suasana reduksi, dimana jumlah kebutuhan oksidan lebih rendah dibandingkan jumlah untuk reaksi pembakaran stoikiometrik. Gasifikasi menghasilkan gas $\mathrm{CO}, \mathrm{H}_{2}, \mathrm{CO}_{2}, \mathrm{H}_{2} \mathrm{O}$ dan $\mathrm{CH}_{4}$ dan polutan berupa $\mathrm{H}_{2} \mathrm{~S}, \mathrm{HCl}, \mathrm{COS}, \mathrm{NH}_{3}, \mathrm{HCN}$, tar, alkali dan partikulat (Arena, 2012). Perbandingan potensi polutan gas yang dihasilkan dari kedua proses tersebut ditampilkan dalam Tabel 4.

Proses gasifikasi melibatkan banyak reaksi. Reaksi-reaksi tersebut dikelompokkan menjadi beberapa group seperti ditampilkan dalam Tabel 5. Reaksi heterogeneous water shift dan reaksi Boudouard merupakan reaksi utama pembentukan dalam proses gasifikasi. Kedua reaksi ini berjalan lambat karena berada dalam fase padat. Komposisi gas produser keluar gasifier sering dianggap dikendalikan oleh reaksi homogeneous water shift yang berlangsung pada fase gas (Syamsudin, 2014). Reaksi fase gas berlangsung lebih cepat dibandingkan reaksi fase padat.

Di dalam gasifier, bahan karbon mengalami beberapa proses yang berbeda. Tahapan proses yang terjadi di dalam reaktor gasifikasi ditampilkan dalam Gambar 2. Pada proses gasifikasi, sludge cake mengalami tahapan proses berturut sebagai berikut (Susanto, 2010).

1. Pengeringan, yaitu sludge cake mengalami pengeringan pada suhu $100-200^{\circ} \mathrm{C}$.

2. Pirolisis (atau devolatilisasi), yaitu penguraian sludge cake akibat dikenai suhu tinggi, mulai sekitar $250^{\circ} \mathrm{C}$ sampai $900^{\circ} \mathrm{C}$. Penguraian sludge cake ini menghasilkan arang, tar, uap senyawa hidrokarbon, air dan gas-gas.

3. Tahap reduksi, di mana terjadi reaksi gasifikasi, yaitu arang bereaksi dengan uap air dan karbon dioksida pada suhu di atas $800^{\circ} \mathrm{C}$. Reaksi ini menghasilkan hidrogen dan karbon monoksida.

4. Tahap oksidasi, di mana terjadi reaksi pembakaran, yaitu gas volatil dan sebagian arang bereaksi dengan oksigen menghasilkan panas yang mendorong berlangsungnya proses pengeringan, pirolisis dan reaksi-reaksi reduksi. Suhu pembakaran dapat mencapai $1200^{\circ} \mathrm{C}$.

Tabel 4. Perbandingan Emisi Polutan dari Simulasi Termodinamika Pembakaran dan Gasifikasi Sludge Cake Pabrik Pulp Kraft (Syamsudin dan Susanto, 2012b)

\begin{tabular}{|c|c|c|c|}
\hline Parameter & Pembakaran $^{1)}$ & Gasifikasi-Udara $^{2}$ & ${\text { Gasifikasi-Kukus }{ }^{3)}}^{3}$ \\
\hline Suhu $\left({ }^{\circ} \mathrm{C}\right)$ & 1700 & $600-1000$ & $800-900$ \\
\hline \multicolumn{4}{|c|}{ Gas Polutan $\left(\mathrm{mg} / \mathrm{Nm}^{3}\right)$ : } \\
\hline a. NO & 3300 & $\approx 0$ & $\approx 0$ \\
\hline b. $\mathrm{NO}_{2}$ & 3 & $\approx 0$ & $\approx 0$ \\
\hline c. $\mathrm{SO}_{2}$ & 1600 & $\approx 0$ & $\approx 0$ \\
\hline d. $\mathrm{SO}_{3}$ & 2 & $\approx 0$ & $\approx 0$ \\
\hline e. $\mathrm{H}_{2} \mathrm{~S}$ & $\approx 0$ & $1500-2100$ & $1250-1550$ \\
\hline f. $\cos$ & $\approx 0$ & $180-200$ & $60-180$ \\
\hline g. $\mathrm{NH}_{3}$ & $\approx 0$ & $0-40$ & $8-12$ \\
\hline h. $\mathrm{HCN}$ & $\approx 0$ & $0,3-0,4$ & $0,05-0,25$ \\
\hline
\end{tabular}


Tabel 5. Reaksi-Reaksi yang Terlibat dalam Gasifikasi

(Higman dan van derBurgt, 2003; Arena, 2012; Syamsudin, 2014)

\begin{tabular}{|c|c|c|c|}
\hline No. & Persamaan & $\mathrm{DH}_{\mathrm{R}, 298}(\mathrm{~kJ} / \mathrm{mol})$ & Nama Reaksi \\
\hline \multicolumn{4}{|c|}{ Reaksi Fase Padat: } \\
\hline 1. & $\mathrm{C}_{(\mathrm{s})}+\mathrm{H}_{2} \mathrm{O}_{(\mathrm{g})} \hat{\mathrm{U}} \mathrm{CO}+\mathrm{H}_{2}$ & 131 & Heterogeneous water shift (primary water-gas) \\
\hline 2. & $\mathrm{C}_{(\mathrm{s})}+2 \mathrm{H}_{2} \mathrm{O}_{(\mathrm{g})} \hat{\mathrm{U}} \mathrm{CO}_{2}+2 \mathrm{H}_{2}$ & 90 & Secondary water gas \\
\hline 3. & $\mathrm{C}_{(\mathrm{s})}+2 \mathrm{H}_{2} \hat{\mathrm{U}} \mathrm{CH}_{4}$ & -75 & Metanasi \\
\hline & $\mathrm{C}_{(\mathrm{s})} \mathrm{CO}_{2} \hat{\mathrm{U}} 2 \mathrm{CO}$ & 173 & Boudouard \\
\hline \multicolumn{4}{|c|}{ Reaksi Fase Gas: } \\
\hline 5. & $\mathrm{CH}_{4}+\mathrm{H}_{2} \mathrm{O}_{(\mathrm{g})} \hat{\mathrm{U}} \mathrm{CO}+3 \mathrm{H}_{2}$ & 206 & Steam methane reforming \\
\hline 6. & $\mathrm{CO}+\mathrm{H}_{2} \mathrm{O}_{(\mathrm{g})} \hat{\mathrm{U}} \mathrm{CO}_{2}+\mathrm{H}_{2}$ & -41 & Homogeneous water shift (water gas-shift) \\
\hline & $\mathrm{CH}_{4}+\mathrm{CO}_{2(\mathrm{~g})} \hat{\mathrm{U}} \mathrm{H}_{2}+\mathrm{CO}$ & 247 & Methane dry reforming \\
\hline \multicolumn{4}{|c|}{ Reaksi-Reaksi Lain: } \\
\hline 8. & $\mathrm{C}(\mathrm{s})+1 / 2 \mathrm{O}_{2}{ }^{\circledR} \mathrm{CO}$ & -111 & Oksidasi parsial karbon \\
\hline 9. & $\mathrm{C}+\mathrm{O}_{2}{ }^{\circledR} \mathrm{CO}_{2}$ & -394 & Oksidasi karbon \\
\hline 10. & $\mathrm{CO}+1 / 2 \mathrm{O}_{2}{ }^{\circledR} \mathrm{CO}_{2}$ & -283 & Oksidasi karbon monoksida \\
\hline 11. & $\mathrm{H}_{2}+1 / 2 \mathrm{O}_{2}{ }^{\circledR} \mathrm{H}_{2} \mathrm{O}_{(\mathrm{g})}$ & -242 & Oksidasi hidrogen \\
\hline 12. & $\mathrm{CH}_{4}+3 / 2 \mathrm{O}_{2}{ }^{\circledR} \mathrm{CO}+2 \mathrm{H}_{2} \mathrm{O}_{(\mathrm{g})}$ & -520 & Oksidasi parsial metana \\
\hline
\end{tabular}

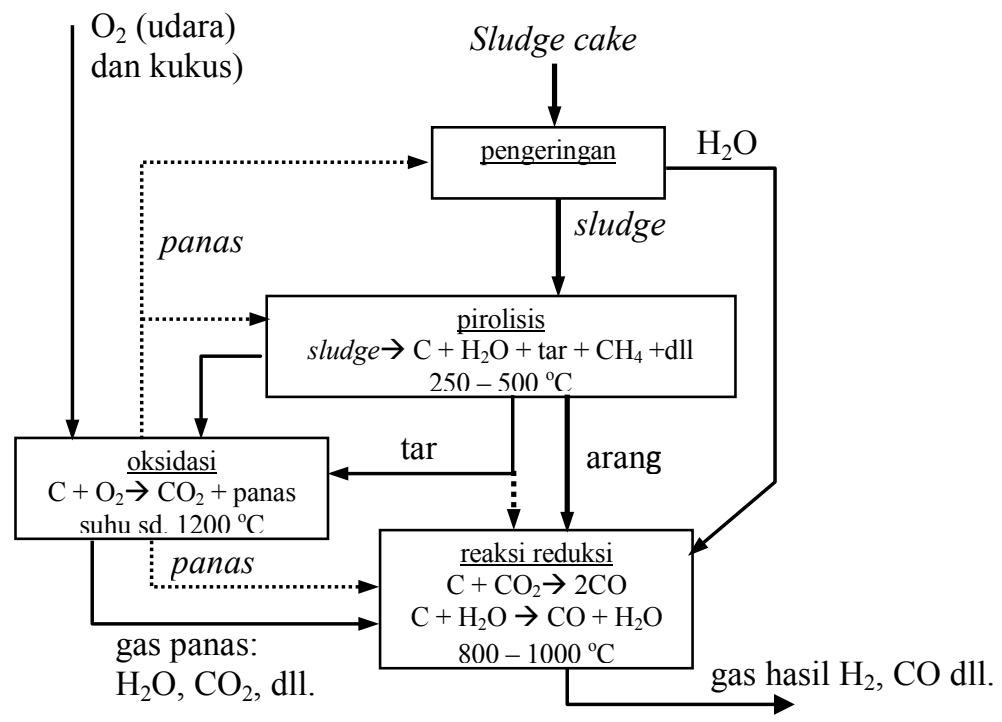

Gambar 2. Diagram Proses Gasifikasi (Susanto, 2010)

Reaksi-reaksi tersebut dapat berlangsung secara bertahap atau secara simultan tergantung konfigurasi reaktor yang digunakan. Pada gasifikasi autothermal, reaksi-reaksi di atas berlangsung dalam satu reaktor sedangkan pada gasifikasi allothermal tahap reaksi oksidasi (bersifat eksotermal) dipisahkan dari tahap reaksi lainnya, yaitu pengeringan, pirolisis dan reduksi (bersifat endotermal).
Udara secara luas telah digunakan sebagai agen gasifikasi karena murah tetapi menghasilkan bahan bakar gas bernilai kalor rendah, seperti yang diterapkan pada konfigurasi autothermal (Gambar 3a). Bahan bakar gas dengan nilai kalor medium dapat diperoleh dengan menerapkan konfigurasi allothermal yang memisahkan antara reaktor pembakaran dan reaktor gasifikasi (Gambar 3b-c). Panas untuk reaksi endotermik 


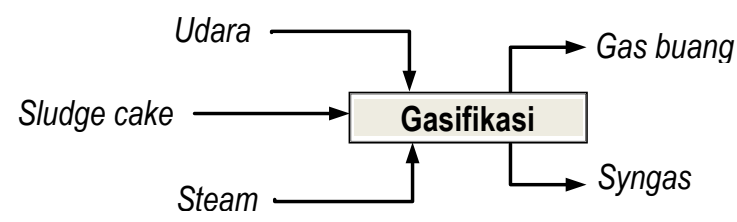

a. Model satu reaktor

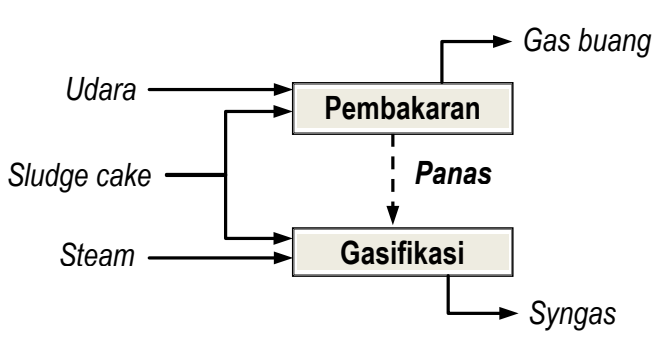

b. Model dua reaktor

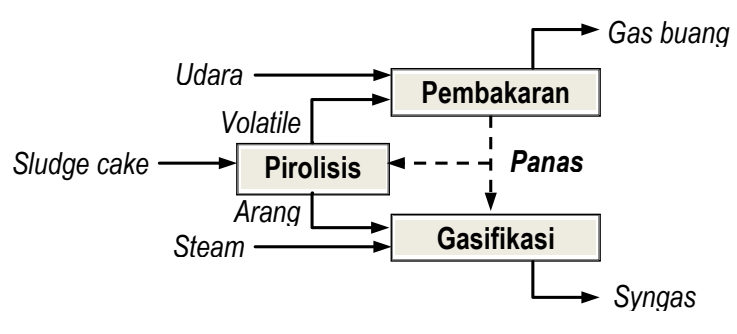

c. Model tiga reaktor

Gambar 3. Konfigurasi Reaktor Gasifikasi Autothermal (a) dan Allothermal (b dan c)

(Pranolo dan Susanto, 2010)

gasifikasi disuplai dari pembakaran sebagian sludge cake (Gambar 3b) atau gas volatil hasil pirolisis (Gambar 3c). Sementara itu, gasifikasi kukus dengan sludge cake atau arang dilaksanakan dalam reaktor unggun terfluidakan terpisah (Pranolo dan Susanto, 2010; Nugrahany dkk., 2012; Nurhadi, 2012). Konfigurasi allothermal dapat menghasilkan bahan bakar gas kualitas medium karena tidak terjadi pengenceran oleh $\mathrm{N}_{2}$ yang berasal dari udara sebagaimana yang terjadi pada reaktor gasifikasi model autothermal (Pranolo dan Susanto, 2010). Gasifikasi sludge cake model dua reaktor memiliki kemampuan menangani sludge cake dengan kadar air tinggi $(<55 \%)$ (Arena, 2012). Kandungan air dalam sludge cake dapat dimanfaatkan sebagai agen gasifikasi sehingga mengurangi kebutuhan kukus. Kelemahan model ini yaitu dihasilkan gas bakar kalor medium dengan kadar tar yang masih tinggi. Sebaliknya, gasifikasi arang model tiga reaktor menghasilkan gas bakar kalor medium dengan kadar tar lebih rendah.

Meskipun demikian, gasifikasi arang model tiga reaktor memerlukan optimasi tingkat pirolisis sludge cake supaya menghasilkan gas volatil yang cukup untuk suplai panas gasifikasi dan yield arang tinggi untuk memaksimalkan produksi gas produser. Jika suplai panas gasifikasi dari pembakaran gas volatil masih kurang, maka dapat ditambahkan suplai panas dari pembakaran sludge cake atau bahan bakar lain.
Pada kajian termodinamika gasifikasi sludge cake menggunakan konfigurasi proses dua tahap, yaitu: (i) proses pirolisis yang menghasilkan arang dan gas volatil, dan (ii) gasifikasi arang hasil pirolisis yang dilakukan oleh Nugrahany, dkk. (2012) menunjukkan bahwa reaksi arang hasil pirolisis dengan kukus dapat menghasilkan bahan bakar gas dengan kalor bakar medium dan kandungan tar minimal. Di samping itu, panas reaksi endotermik untuk proses gasifikasi dapat dipenuhi dari pembakaran gas volatil hasil pirolisis sludge cake pada suhu pirolisis $500^{\circ} \mathrm{C}$. Hasil kajian oleh Syamsudin dan Susanto (2012a) menunjukkan bahwa proses gasifikasi-kukus model allothermal terhadap arang sludge cake dapat menghasilkan gas bakar dengan nilai kalor $11 \mathrm{MJ} / \mathrm{Nm}^{3}$ dan konsentrasi tar relatif rendah.

Percobaan gasifikasi arang sludge cake dan arang batubara oleh Syamsudin (2014) menunjukkan bahwa karbon dalam arang sludge cake lebih reaktif dibandingkan karbon dalam arang batubara. Gasifikasi arang sludge cake mulai berlangsung pada suhu lebih rendah, ditunjukkan dengan puncak yang sangat tajam pada suhu $850^{\circ} \mathrm{C}$ dan laju kenaikan suhu yang tinggi selama pirolisis menghasilkan arang yang lebih reaktif untuk gasifikasi. Reaktivitas arang dengan kukus lebih tinggi dibandingkan reaktivitasnya dengan gas $\mathrm{CO}_{2}$ dilihat dari laju gasifikasi yang lebih tinggi. Fenomena ini sesuai dengan teori yang disampaikan oleh Chen, dkk. (2012) 
yang menyebutkan bahwa kukus $\left(\mathrm{H}_{2} \mathrm{O}\right)$ lebih mudah teradsorpsi pada permukaan arang karena energi aktif adsorpsi $\mathrm{H}_{2} \mathrm{O}$ yang lebih rendah dibandingkan energi aktif adsorpsi $\mathrm{CO}_{2}$. Jika dibandingkan dengan arang batubara, maka arang sludge cake bersifat lebih reaktif. Kereaktivitasan arang sludge cake kemungkinan disebabkan oleh struktur partikel dan efek katalitik dari logam (inherent catalyst: $\mathrm{Na}, \mathrm{Ca}, \mathrm{Mg}$ dan $\mathrm{K}$ ) yang terdapat dalam sludge cake.

\section{APLIKASI GASIFIKASI SLUDGE CAKE DI PABRIK PULP KRAFT}

Bahan bakar yang paling umum digunakan sebagai sumber energi untuk lime kiln adalah bahan bakar minyak dan gas bumi. Di pabrik pulp modern, lime kiln merupakan satu-satunya pengguna bahan bakar fosil. Penggantian bahan bakar fosil dengan gas hasil gasifikasi sludge cake dapat memberi manfaat ekonomi dan lingkungan yang signifikan menuju industri pulp dengan zero fossil fuel. Gasifikasi telah diaplikasikan selama bertahun-tahun untuk menyediakan bahan bakar gas-bersih untuk lime kiln. Gas hasil gasifikasi memungkinkan dibakar dengan baik dan stabil di lime kiln dengan kapasitas produksi dan heat rate serupa dengan gas bumi.
Gas buang panas hasil pembakaran di lime kiln dimanfaatkan sebagai gas pengering sludge cake di dalam pengering unggun terfluidakan. Selanjutnya, gas buang yang banyak mengandung gas $\mathrm{CO}_{2}$ hasil kalsinasi dan pembakaran ini dapat dimanfaatkan sebagai agen gasifikasi bersama kukus sehingga dapat meningkatkan proses gasifikasi sekaligus mengurangi emisi $\mathrm{CO}_{2}$. Batubara atau limbah biomassa pabrik pulp lainnya dapat ditambahkan untuk meningkatkan kualitas bakar sludge cake atau menambah pasokan panas yang diperlukan untuk proses pirolisis dan gasifikasi allothermal. Konfigurasi proses integrasi unit gasifikasi sludge cake untuk penghematan gas bumi untuk lime kiln di unit pemulihan bahan kimia di pabrik pulp kraft ditampilkan dalam Gambar 4. Hasil simulasi termodinamika oleh Syamsudin dan Susanto (2012a) menunjukkan dengan ketersediaan sludge cake $95 \mathrm{~kg}$ per ton $\mathrm{CaO}$ dan konsumsi gas bumi $218 \mathrm{Nm}^{3}$ per ton $\mathrm{CaO}$ untuk bahan bakar lime kiln di pabrik pulp kraft (suhu kalsinasi $1000^{\circ} \mathrm{C}$ ), maka pemanfaatan sludge cake sebagai bahan bakar gas melalui proses gasifikasi-kukus dapat menggantikan sebagian gas bumi tersebut sampai $18 \%$. Besarnya penggantian gas bumi dibatasi oleh ketersediaan sludge cake dan suhu pembakaran yang bisa dicapai. Karena panas pembakaran gas produser relatif lebih rendah daripada gas bumi,

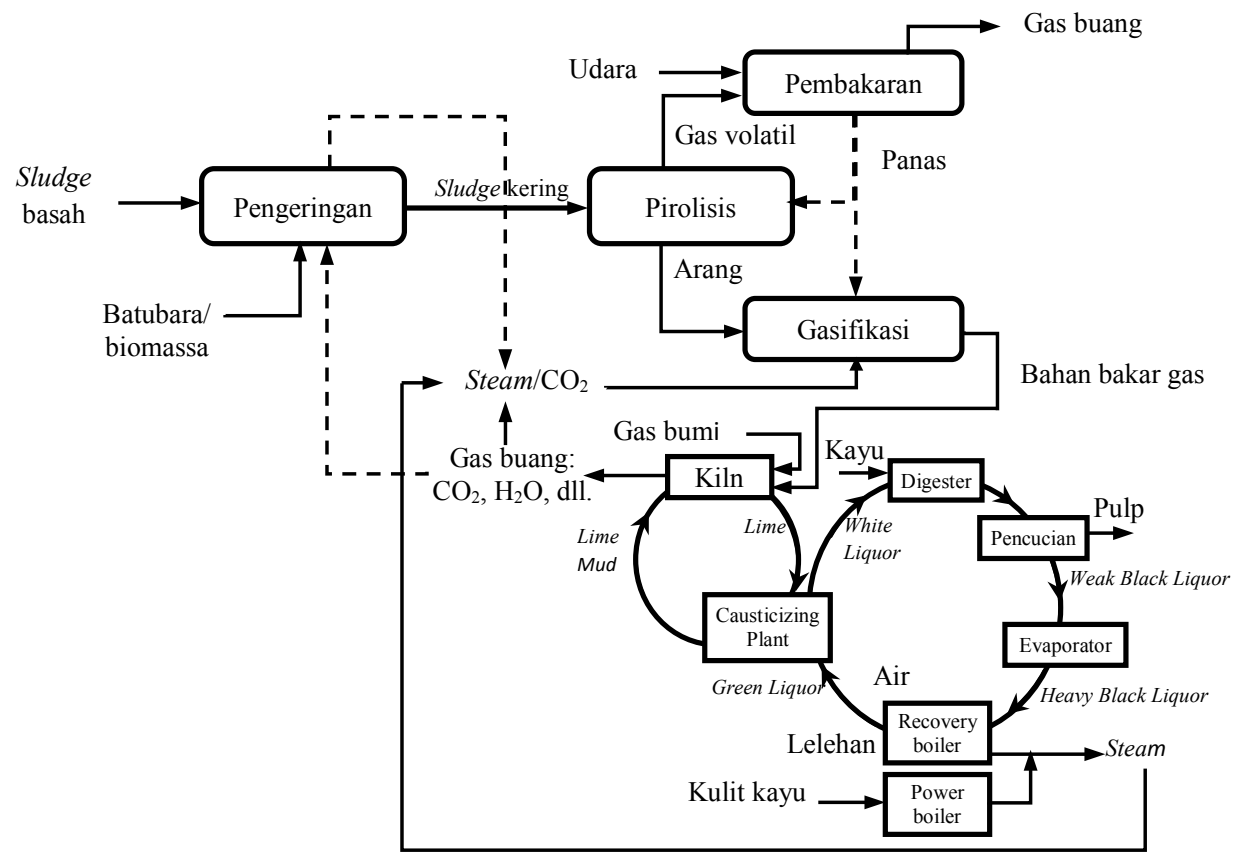

Gambar 4. Konfigurasi Proses Integrasi Unit Gasifikasi Sludge Cake di Unit Pemulihan Kimia Pabrik Pulp Kraft (Syamsudin, 2014) 
maka penggantian gas bumi dengan gas produser dapat mengakibatkan laju alir gas bahan bakar meningkat sehingga perlu redesign sistem aliran gas, perbandingan udara/gas bahan bakar turun sehingga perlu pengaturan air/fuel ratio, dan kapasitas pemanasan (heating rate) turun sehingga perlu redesign burner dan furnace.

\section{KESIMPULAN}

Sludge cake dapat dimanfaatkan sebagai energi alternatif melalui gasifikasi untuk menghasilkan bahan bakar gas medium. Kendala kadar air tinggi dan sifat dewaterability rendah dapat diatasi dengan penambahan media bantu filtrasi memanfaatkan limbah biomassa pabrik pulp dan proses dewatering dengan metode TAMD. Pengeringan dapat dilanjutkan dengan pengering unggun terfluidakan memanfaatkan gas panas dari boiler atau lime kiln. Bahan bakar gas dengan nilai kalor medium dapat diperoleh dari sludge cake melalui gasifikasi allothermal. Gasifikasi allothermal model dua reaktor mampu menangani sludge cake dengan kadar air tinggi $(<55 \%)$ namun menghasilkan gas dengan kandungan tar yang masih tinggi. Gasifikasi atau pembakaran sludge cake pada model ini sebaiknya dilakukan pada suhu di bawah $1200^{\circ} \mathrm{C}$ untuk menghindari terjadinya slagging dan fouling. Sebaliknya, gasifikasi allothermal model tiga reaktor dapat menghasilkan gas dengan kandungan tar rendah. Tahap pirolisis pada model ini dilakukan pada suhu $<500^{\circ} \mathrm{C}$ dengan mempertimbangkan kecukupan suplai panas gasifikasi dan yield arang tinggi. Gas hasil gasifikasi memungkinkan dibakar dengan baik dan stabil di lime kiln dengan kapasitas produksi dan heat rate serupa dengan gas bumi. Penggantian gas bumi dengan gas produser perlu memperhatikan redesign proses pembakaran terkait dengan panas pembakaran yang lebih rendah.

\section{DAFTAR PUSTAKA}

Arena, U., 2012. Process and Technological Aspects of Municipal Solid Waste Gasification. A Review. Waste Management. Vol. 32, 625-639.

Balat, M., Balat, M., Kirtay, E., Balat, H., 2009. Main Routes for the Thermo-Conversion of Biomass into Fuels and Chemicals. Part 2: Gasification Systems. Energy Conversion and Management. Vol. 50, 3158-3168.
Chen, C., Wang, J., Liu, W., Zhang, S., Yin, J., Luo, G., Yao, H., 2012. Effect of Pyrolysis Conditions on the Char Gasification with Mixtures of $\mathrm{CO}_{2}$ and $\mathrm{H}_{2} \mathrm{O}$. Proceedings of the Combustion Institute. Vol. $\mathbf{x x x}, \mathrm{xxx}-\mathrm{xxx}$.

Chen, G., Yue, P.L., Mujumdar, A.S., 2006. Dewatering and Drying of Wastewater Treatment Sludge. Taylor \& Francis, 887-902.

Fernandez, A., Arlabosse, P., Descoins, N., 2005. Thermally Assisted Mechanical Dewatering: State of the Art and New Developments. Chemical Engineering Transactions. Vol. 7, 737-742.

Gao, N., Li, A., Quan, C., Gao, F., 2008. Hydrogen-Rich Gas Production from Biomass Steam Gasification in an Updraft Fixed-Bed Gasifier Combined with a Porous Ceramic Reformer. Int J Hydrogen Energy. Vol. 33, 5430-5438.

Gavrilescu, D., 2008. Energy from Biomass in Pulp and Paper Mills. Environmental Engineering and Management Journal. Vol. 7(5), 537-546.

Higman, C., Van derBurgt, M., 2003. Gasification. Gulf Professional Publishing, Burlington, USA.

Ineris, 2010, http://aida.ineris.fr/bref/brefpap/ bref_pap/english/bref_gb_kraft_niveau.htm, diakses 15 Juli 2013.

Khalil, R., Varhegyi, G., Jaschke, S., Gronli, M.G., Hustad, J., 2009. $\mathrm{CO}_{2}$ Gasification of Biomass Chars: A Kinetic Study. Energy Fuels. Vol. 23, 94-100.

Kumar, A., Eskridge, K., Jones, D.D., Hanna, M.A., 2009. Steam-Air Fluidized Bed Gasification of Distillers Grains: Effects of Steam to Biomass Ratio, Equivalence Ratio and Gasification Temperature. Bioresour. Technol. Vol. 100, 2062-2068.

Louhimo, J.T., Mullen, J.F., 1991. Sludge Burning in Fluidized Bed Boilers, 101-116 dalam Coleman, M.J., Ed, Energy Engineering and Management in the Pulp and Paper Industry. TAPPI Press, Atlanta.

Mahmood, T., Zawadski, M., Banerjee, S.,1998. Pilot Study of Impulse Drying - Industrial Sludge. Environ Sci Technol. Vol. 32, No. 12, 1813-1816.

Mahmoud, A., Arlabosse, P., Fernandez, A., 2011. Application of a Thermally Assisted Mechanical Dewatering Process to Biomass. Biomass and Bioenergy. Vol. 35, 288-297.

Mahmoud, A., Fernandez, A., Arlabosse, P., 2008. Thermally Assisted Mechanical Dewatering (TAMD) of Suspensions of Fine Particles: Analysis of the Influence of the Operating Conditions Using the Response Surface Methodology. Chemosphere. Vol. 72, No. 11, 1765-1773. 
Nugrahany, F., Safitri, N.G., Syamsudin, Susanto, H., 2012. Study on Reactor Configuration for Air/Steam Gasification of Sludge Cake to Produce Medium Heating Value Gas. Prosiding on $19^{\text {th }}$ Regional Symposium of Chemical Engineering, Bali.

Nurhadi, 2010. Pengembangan Konfigurasi Proses Gasifikasi Allothermal dengan Umpan Arang Hasil Pirolisis. Thesis, Institut Teknologi Bandung.

Pranolo, S.H., Susanto, H., 2010. Kajian Termodinamika Konfigurasi Reaktor Gasifikasi untuk menghasilkan Gas Sintesis. Prosiding Seminar Nasional Soebardjo Brothohardjono VII, Surabaya.

Qi, Y., Thapa, K.B., Hoadley, A.F.A., 2011. Application of Filtration Aids for Improving Sludge Dewatering Properties - A Review. Chemical Engineering Journal. Vol. 171, 373-384.

Richards, J.R., 2000. Control of Gaseous Emissions, Student Manual. US EPA, 8.19.30.

Scott, G.M., Abu bakr, S., Smith, A., 1995. Sludge Characteristics and Disposal Alternatives for the Pulp and Paper Industry. Proceedings of the 1995 International environmental conference. TAPPI Press, Atlanta, 269-279.

Setiadji, 2002. Sistem Pembakaran Limbah Lumpur Pabrik Pulp dan Kertas untuk Boiler. Prosiding Seminar Teknologi Selulosa. Balai Besar Selulosa, 165-170.
Setiawan, Y., Purwati, S., Wardhana, K.A., Surachman, A., Wattimena, R.B., 2012. Potency of Solid Waste of Paper Mill Using Recycle Paper as Fuel. Jurnal Selulosa. Vol. 2, No. 2, 81-87.

Susanto, Herri, 2010. Sekilas Teknologi Gasifikasi.http://esptk.fti.itb.ac.id/herri/ index.html, diakses pada tanggal 10 Juni 2013.

Syamsudin, Purwati, S., Rostika, I., 2007. Pemanfaatan Campuran Limbah Padat dengan Lindi Hitam dari Industri Pulp dan Kertas Sebagai Bahan Biobriket. Berita Selulosa. Vol. 42, No. 2, 68-75.

Syamsudin, 2014. Gasifikasi Sludge Cake Pabrik Pulp Kraft untuk Produksi Bahan Bakar Gas - Kinetika Pirolisis dan Gasifikasi Arang. Disertasi, Institut Teknologi Bandung, Bandung, Indonesia.

Syamsudin, Susanto, H., 2012a. Study of Alternative Fuels for Lime Kiln in the Kraft Pulp Mill. Jurnal Selulosa. Vol. 3, No. 1, 4350.

Syamsudin, Susanto, H., 2012b. Evaluation on Potential Emission of Gaseous Polutants in Utilization of Sludge Cake from Pulp Mills for Alternative Energy Resources. Proceeding of the 19th Regional Symposium on Chemical Engineering (RSCE 2012), Bali.

Yang, H., Yan, R., Chen, H., Lee, D.H., Zheng, C., 2007. Characteristics of Hemicelluloses, Cellulose and Lignin Pyrolysis. Fuel. Vol. 86, 1781-1788. 
Jurnal Selulosa, Vol. 5, No. 1, Juni 2015:7-20 